\title{
Analysis of Load Control Strategy
}

\author{
Junxia Qian \\ Jiangsu Keneng Electric Power Engineering Consulting Co.,LTD, Nanjing 210036, China. \\ qianjunxia@jspdi.com.cn
}

\begin{abstract}
In the paper a management scheme is proposed. Firstly, the yardstick competition is applied to optimize the electricity energy rationing model to realize maximum energy consumption efficiency. Secondly, the objective of load control is to achieve the maximum of energy consumption efficiency and the minimization of the operation time. The optimization management based on the interruptible load is developed, and the combined heuristic NSGA- II algorithm is proposed with the gene correction module to solve the optimal problem. Finally, the feasibility and effectiveness of the method proposed in the paper is proved by the research results.
\end{abstract}

Keywords: Strategy; Power consumption; Load control.

\section{Introduction}

With the popularity of smart meter in smart grid, the system operator can take many kinds of load control measures to improve the operation efficiency and power quality of distribution network. Load reduction in the load management measures includes the direct load control (DLC) and the demand side response (DR), which is all based on the smart meter. The DLC sends control signal through the operators to interrupt the subscribers' power [1], and DR is dependent on the signal of real-time price [2-5].

To solve the above problem, this paper proposes a two-stage optimization strategy. At the first stage, we propose the high energy consumption enterprise power allocation scheme considering the energy efficiency. The second stage is load management optimization strategy, it optimizes the order of load in each period to avoid important load power outages and eliminate the load rebound effect. Finally, the feasibility and effectiveness of the method are verified by a numerical example.

\section{Optimization strategy for load management considering energy efficiency}

The power consumption of high energy consumption enterprises accounted for mostly of total power consumption of whole society. Limiting their power consumption can make obvious effect and improve the overall energy efficiency of the system obviously. And it accords with regulations for orderly use of electricity of China. But when we want to limit the power of these enterprises, we can only interrupt power supply though disconnecting switches in distribution network not though terminal control. For the interruptible load which terminal is controllable, it can be controlled directly according to the system demand. But it's interrupt quantity is small, it will be used to increase the load transfer capacity and reduce the load rebound effect [6].

A two-stage management scheme is proposed in this paper. At the first stage, the yardstick competition is applied in the optimal electricity energy rationing model to realize maximum energy consumption efficiency. At the second stage, the objective of the model is to obtain the maximum of energy consumption efficiency and the minimization of the switch operation time, the loss of the priority load as well as the interruptible load. At the same time, the interruptible load can be further implemented avoiding the load rebound effect in the process of load recovery. Increasing the load transfer line capacity will ensure the power supply of important subscribers. The load management optimization strategy process considering energy efficiency is shown in Figure 1 [7]. 


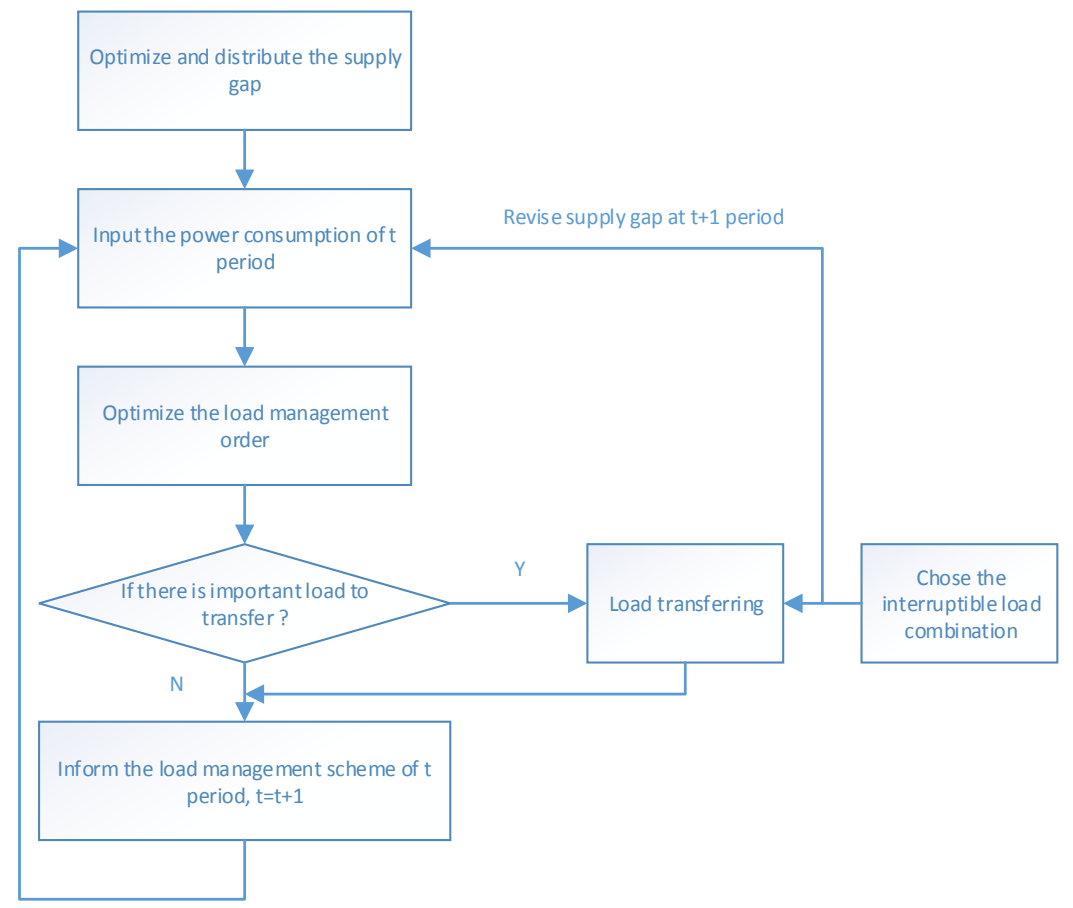

Fig.1 Flow chart of optimized strategy for load control

\section{Mathematical models}

\subsection{Electricity energy rationing model based on the yardstick competition of energy efficiency}

In this paper, the energy efficiency index is used as the principle of power supply to the high energy consumption enterprises. According to the principle of fairness, if the energy consumption of high energy consumption enterprises is lower than average level, the amount of supply will be increased to inspire the energy efficiency so that they can obtain enough power to product. And conversely, they will obtain more power to make profit.

Objective function:

$$
F=\min \left(\sum_{i=1}^{n} \alpha_{i} E X_{i}\right)
$$

Constraint condition:

$$
\sum_{i=1}^{n} \alpha_{i}=1
$$

In (2), E is the power gap value which is obtained according to the system load forecasting results and power generation capacity. $\alpha_{\mathrm{i}}$ is load gap ratio of high energy consumption subscriber $\mathrm{i}, \mathrm{X}_{\mathrm{i}}$ is energy efficiency index of high energy consumption subscribers $i$, which dimension is one. The solving process is as follows.

\subsection{Optimal operation model of load management considering energy efficiency}

In the operation of load management, the rules are made as follows:

1) Ration the power supply especially the high energy consumption subscribers.

2) Divide the load into three parts when the power is in shortage: the load that cannot interrupt, partly interrupt and totally interrupt.

3) Consider the load every period after ration the power supply and after it recovers, the load rebound effect for the next period of time should meet the system demand.

\section{Case analysis}

In this paper, the structure of the distribution network in the literature has been changed. Total active load of the system is $5.87 \mathrm{MW}$.The active load gap is $0.63 \mathrm{MW}$. 
The comparison of rationing scheme of load management is listed in Table 1.

According to the current load management method, rationing the power supply is on the basis of the historical energy consumption. And important subscribers are involved in operation. According to the rationing scheme in this paper, we ensure the power supply of important subscribers by controlling the interruptible load in the line containing the important subscribers. The implement of interruptible load eliminate the load rebound effect.

The comparison of energy efficiency and reliability. Energy conservation effect and load loss are listed in Table 2. In Table 2, the entire energy efficiency is the opposite number of target function value after rationing. The method makes the energy efficiency promote $43.3 \%$ and the outage of important subscribers reduces $55.7 \%$. It improves the stability of system.

Table 1 comparison between original and optimized load management schemes

\begin{tabular}{cc}
\hline Load management strategy & The strategy of rationing supply \\
\hline Initial strategy & $8,9,11,13,14,16,17,18,20,28,30,31,39$ \\
Optimized strategy & $39,46,48,49,51,52,61,11,16,30,34,35,41$ \\
\hline
\end{tabular}

Table 2 Comparison of energy conservation and loss of high priority load

\begin{tabular}{ccc}
\hline Load management strategy & $\begin{array}{c}\text { The entire energy consumption } \\
\text { efficiency }\end{array}$ & The loss of important load \\
\hline Initial strategy & -1.19 & 0.95 \\
Optimized strategy & -0.83 & 0.42 \\
\hline
\end{tabular}

\section{Conclusion}

In this paper, a 2-stage load management optimization model is established. The case improved the effectiveness of the model and strategy by comparing the results and the energy efficiency index and reliability index of the initial strategy and the optimal strategy. It provided a reference for load management method in the new situation of smart grid.

\section{References}

[1] ISAKSENL. MAFS. SIMONS N W, et al. Bibliography on load management [J]. IEEE Trans on Power Apparatus and Systems, 1981, 100(5): 2597-2601.

[2] AALAMIH, YOUSEFI G R, MOGHADAM M P. Demand response model considering EDRP and TOU programs[C]// Proceeding of the 2008 IEEE/PES Transmission and Distribution Conference and Exposition (R\&D’08), April 21-24, 2008, Chicago, IL, USA; 6p.

[3] KURUCZ C N, BRANDT D, SIM S. A linear programming model for reducing system peak though customer load control programs [J]. IEEE Trans on Power System, 1996, 11 (4): $1817-1824$

[4] LIU Jian, WANG Shuanghu, MING Zhengfeng. Optimal peak load shifting plan for demand side management [J]. Automation of Electric Power Systems, 2006, 30(8): 47-50

[5] HUANG K Y. Demand subscription services-an iterative dynamic programming for the substation suffering from capacity shortage [J]. IEEE Trans on Power Systems, 2003, 18(2): 947-953.

[6] HUANG Xianchao, ZHANG Lizi, TAYLOR G. Service restoration of power distribution systems with load control [J]. Automation of Electric Power Systems, 2010, 34(17):22-26.

[7] KUMAR Y,DAS B,SHARMA J. Multiojective, multiconstraint service restoration of electric power distribution system with priority customers [J]. IEEE Trans on Power Delivery, 2008, 23(1): 261-269. 